\title{
INFARTOS CEREBRAIS EM PACIENTES JOVENS RELACIONADOS A DEFICIÊNCIA DE ANTICOAGULANTES NATURAIS
}

\author{
PROTEÍNA C E PROTEÍNA S
}

\author{
JOSÉ IBIAPINA SIOUEIRA NETO*, ANTONIO C. SANTOS**, \\ SORAIA R. CABETTE FÁBIO***, AMÉRICO C. SAKAMOTO****
}

\begin{abstract}
RESUMO - Infartos cerebrais (IC) em jovens apresentam múltiplas etiologias que diferem do padrāo observado nos indivíduos idosos. Deficiências de anticoagulantes naturais têm sido descritas nos últimos anos como causa de IC, principalmente em pacientes com menos de 40 anos. Existe tendência atual de se pesquisar essas deficiências em todos os pacientes jovens com infarto cerebral de causa indeterminada e naqueles com manifestaçס̄es trombóticas de múltiplos sistemas. Realizamos pesquisa dos níveis de proteína C, proteína $\mathrm{S}$ e antitrombina III em pacientes entre 15 e 40 anos com ICs classificados como indeterminados após conclusão de protocolo básico de investigação. Diagnosticamos dois casos de deficiência de proteína $\mathrm{Ce}$ um caso de deficiência de proteína $S$. Concluímos que a investigação sistemática de causas hematológicas proporciona decréscimo no número de infartos indeterminados, além de possibilitar a adoção de condutas específicas que diminuem a incidência de novos eventos nos casos diagnosticados.
\end{abstract}

PALAVRAS-CHAVE: infarto cerebral, pacientes jovens, proteina $C$, protefna $S$, anticoagulantes naturais.

\section{Protein $\mathbf{C}$ and $\mathbf{S}$ deficiencies related stroke in young patients}

ABSTRACT - The possible etiologies of cerebral infarcts (CI) in young patients differ from those in the older stroke population. Recently, deficiencies of fibrinolytic factors emerged as an important etiology of stroke in the young population. The literature has emphasized the diagnosis of such conditions especially in stroke cases of undetermined etiology and with history of recurrent thrombosis. We carried out a research on the serum level of protein C, protein S, and antithrombin III in young patients, between 15 and 40 years, with CI of undetermined cause after application of a standard protocol. Three patients had low levels of these proteins: two had protein C deficiency, and one protein $S$ deficiency. None of them had antithrombin III deficiency. We conclude that systematic investigation of such causes of cerebral infarct will reduce the group of undetermined strokes, and will open the possibility of prophylactic treatment in a non-negligible group of patients.

KEY WORDS: cerebral infarct, young patient, protein C deficiency, protein S deficiency.

Infartos cerebrais (IC) em jovens eram considerados, pelos primeiros autor que estudaram o assunto, eventos de ocorrência pouco frequente ou até mesmo rara. Adams et al. ${ }^{2}$ relataram em 1986 que 3\% dos ICs ocorrem em pacientes entre 15 e 45 anos. Já Bogousslavsky \& Pierre ${ }^{7}$ em 1992 relataram que, entre mais de 1600 pacientes admitidos com o primeiro evento isquêmico cerebral,

*M.D., Professor Adjunto Doutor do Departamento de Medicina Clínica da Universidade Federal do Ceará; **M.D., Professor Assistente de Neurorradiologia do Departamento de Clínica Médica da Faculdade de Medicina de Ribeirăo Preto (FMRP) da Universidade de Sāo Paulo (USP); ***M.D., Médica Assistente do Departamento de Neurologia, Psiquiatria e Psicologia Médica da FMRP/USP; ****M.D., Professor Associado do Departamento de Neurologia, Psiquiatria e Psicologia Médica da FMRP/USP. Aceite: 4-junho-1996.

Dr. José Ibiapina Siqueira Neto - Av. Historiador Raimundo Girão 444/701 - 60165-050 Fortaleza CE - Brasil. 
$12,3 \%$ (202 casos) tinham menos de 45 anos. Apesar das diferenças de proporções relatadas, hoje se sabe que ICs em jovens estāo longe de se constituir raridade. Existem diferenças importantes de etiologia nesses pacientes, quando comparados aos de faixa etária mais avançada. Deficiências de inibidores da coagulação têm sido relacionadas nos últimos anos entre as etiologias de infarto cerebral em pacientes jovens, sendo infrequente em outros grupos etários. No nosso país poucos seviços estudam sistematicamente alteraçōes de coagulação em pacientes jovens.

Procuramos averiguar a incidência destas deficiências em uma população de pacientes jovens com diagnóstico previo de IC de origem indeterminada.

\section{CASUÍSTICA E MÉTODO}

Realizamos dosagens de fatores anticoagulantes naturais em 31 pacientes com infarto cerebral entre 15 e 40 anos. Quinze pacientes foram submetidos a dosagem de proteína C e 25 a dosagem de proteína S. Em 29 pacientes a antitrombina III foi também estudada. Esses pacientes foram submetidos previamente, no setor de Doenças Neurovasculares do Hospital das Clínicas de Ribeirão Preto (HCRP), a protocolo básico de investigaçāo diagnóstica para pacientes jovens com infarto cerebral que incluiu, além dos exames laboratoriais de rotina, os seguintes exames de imagem: tomografia computadorizada de crânio (TC) ultra-sonografia de carótidas e ecodopplercardiograma transtorácico. Na avaliação laboratorial foram pesquisados anticorpos antifosfolípides através de teste imunologico para deteç̧ão do anticorpo anticardiolipina e de ensaio de coagulaçăo para o inibidor lúpico. A angiografia cerebral convencional ou de subtraçāo foi realizada em todos os casos năo elucidados por outras provas diagnósticas "nāo-invasivas".

Realizamos no HCRP dosagem de inibidores da coagulaçãa em pacientes com infarto cerebral e: trombose venosa central, antecedentes de trombose venosa profunda de repetiçăo, história familiar positiva para doenças trombóticas e nos casos sem definição etiológica após a angiografia cerebral (infartos indeterminados). Os critérios empregados para classificação dos infartos cerebrais foram os preconizados pelo TOAST', próprio para estudos multicêntricos, que os subdividem em 5 grupos: [1] aterosclerose de grandes artérias; [2] lacunares; [3] cardioembólicos; [4] por outras etiologias; [5] indeterminados.

As dosagens de proteína C, proteina S e antitrombina III foram realizadas no Laboratorio de Hematologia e o método utilizado foi o "endpoint essay" (cromogênico) com substratos (reagentes) comerciais. Valores abaixo de $70 \%$ foram considerados compatíveis com o diagnóstico de deficiência desses fatores. As amostras foram colhidas no mínimo três meses após o icto, como preconizado por High ${ }^{13}$. Pacientes com resultados positivos nos ensaios imunologicos foram submetidos a método funcional para confirmação diagnóstica. Solicitamos tambem nestes casos dosagem em outra amostra ou ainda em parentes de primeiro grau, mesmo sem história clínica de trombose's.

\section{RESULTADOS}

Diagnosticamos um (4,00\%) caso de deficiência de proteína $S$, dos 25 pacientes estudados, e dois $(13,35 \%)$ casos de deficiência de proteína $C$, dos 15 pacientes estudados. Não foram diagnosticados casos de deficiência de antitrombina III. Nossa amostragem não permitiu a aplicaçāo de testes para avaliar a significância estatística dos resultados, devido ao pequeno número de pacientes estudados. Vinte e dois $(\mathbf{7 0 , 9 5 \% )}$ pacientes foram submetidos a angiografia cerebral dentre os 31 que tiveram ao menos um destes anticoagulantes naturais.

A primeira paciente com deficiência de proteína $\mathrm{C}$ apresentou icto 4 dias após parto cesáreo não complicado. $O$ único fator de risco que relatava era o uso prévio de anticoncepcionais e não apresentou qualquer evidência de eclâmpsia nesse perfodo. $O$ quadro se iniciou com cefaléia intensa sem perda da consciência, sendo seguido de hemiparesia esquerda (E). Na TC apresentava, além da lesão mal definida em região parietal direita (D) (Fig 1), múltiplas áreas hipodensas bem definidas em regiāo parietal $\mathrm{E}$, ínsula e hemisfério cerebelar $\mathrm{D}$, sugestivas de comprometimento de múltiplos territórios arteriais (Fig 2). Os outros infartos não tiveram tradução clínica. A dosagem de proteína C mostrou-se baixa, tanto no método imunológico (65\%) como no funcional (48\%). 


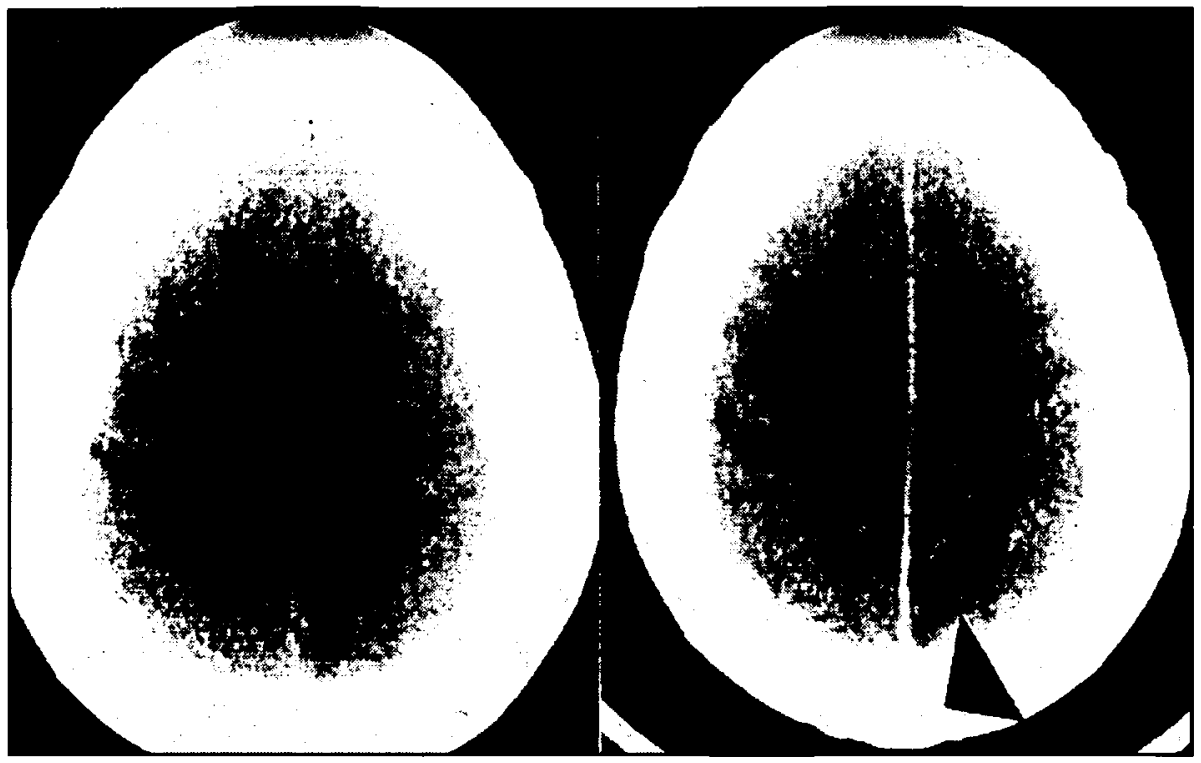

Figs l e 2. Caso 1. TC mostra área de infarto parietal direito recente e área de infarto parietal esquerdo antigo em paciente com deficiência de proteína $C$ e comprometimento de múltiplos territórios arteriais.

A segunda paciente com deficiência de proteína $\mathrm{C}$ apresentou quadro súbito de hemiparesia $\mathrm{E}$ com perda da consciência. Na angiografia apresentava obstrução do tipo trombose "in situ" da carotida interna $\mathrm{D}$, sem qualquer evidência de aterosclerose. Tinha relato de uso de anticoncepcional oral, sem outros antecedentes. Na dosagem de proteína $\mathrm{C}$ detectamos baixos níveis em duas amostras consecutivas $(60 \%)$.

A terceira paciente apresentava deficiência de proteína $S$ e tinha quadro clínico de cefaléia intensa com vômitos, confusão mental e déficit motor a D. Relatava uso de anticoncepcionais orais, tromboses venosas em membros inferiores e migrânia complicada. Lesões parietais altas bilateralmente foram detectadas na TC (Fig 3). A topografia das lesões sugeria trombose de seio sagital superior, mas a angiografia cerebral realizada depois da fase aguda não mostrou alterações, possivelmente por recanalização do seio. $O$ diagnóstico de alteração pró-trombótica foi confirmado com a detecção de niveis baixos de proteína $S$ através do método imunológico (50\%). Dosamos a proteína $S$ da mãe desta paciente que também apresentava nível abaixo do normal (66\%).

Propusemos anticoagulação para as Pacientes 1 e 3, que não aceitaram a conduta e não compareceram mais ao ambulatório, perdendo-se assim o seguimento. A Paciente recente com transformação hemorrágica em paciente com 2, com trombose "in situ" da carótida interna D, deficiência de proteína S. 
foi tratatada com antiagregantes em decorrência da inexistência de qualquer outra manifestação trombótica. Evolui sem apresentar novos eventos, após dois anos de acompanhamento.

Outros três pacientes apresentavam níveis compatíveis com o diagnóstico de deficiência, mas nāo confirmamos esta hipótese nestes casos. $O$ primeiro tinha hipertensão arterial e apresentou hemorragia intraparenquimatosa no segundo icto, ficando com diagnóstico de infarto lacunar para o primeiro evento. $O$ segundo apresentava plaquetose, inibidor lúpico inconclusivo, anticorpo anticardiolipina limítrofe, além da "deficiência" de proteína $\mathrm{C}$, que poderiam ter provocado infarto por hipercoagulabilidade. $\mathbf{O}$ último destes apresentava quadro clínico e angiográfico compatíveis com arteriopatia de moyamoya e atribuímos os níveis baixos de proteína $\mathrm{C}$ à colheita da amostra efetuada nos dias seguintes a um episódio de déficit motor focal transitório.

\section{DISCUSSÃO}

Encontra-se bem estabelecido que infartos cerebrais em pacientes jovens apresentam um grande número de etiologias ${ }^{1,2,6,7,14}$. Nos últimos anos vários autores têm relatado alterações de coagulação como fator etiológico em infartos cerebrais em pacientes com menos de $\mathbf{4 0}$ anos. Baixos níveis de proteínas anticoagulantes naturais (proteína $C$, proteína $S$, antitrombina III) sāo responsáveis por lesōes cerebrais isquêmicas focais em alguns pacientes que previamente seriam classificados no grupo de infartos indeterminados ${ }^{17}$. $O$ desequilíbrio gerado pelo mal funcionamento da cadeia fibrinolítica provocaria desvio da homeostase no sentido pró-trombótico nestes pacientes ${ }^{13.20}$.

Existem relatos de casos de infarto cerebral atribuídos a defíciência de proteína $\mathrm{C}^{16,18,20,21,24}$. Casos de deficiência de proteína $S$ também já foram descritos ${ }^{5,9,11,12,19,20,23}$. Estas deficiências podem ser hereditárias ou adquiridas. Apenas no estudo de Chancellor et $\mathrm{al}^{8}$ foi relatada ausência de relação positiva entre estas alteraçōes hematológicas e IC. Estes autores fizeram testes de função hemostática em 38 pacientes jovens (menos de 40 anos) com IC e não detectaram anormalidades.

Hart \& Kanter $^{13}$ propuseram investigaçāo sistemática para identificação de doenças prótromboticas em pacientes jovens com infarto de causa "indeterminada". De maneira geral adotamos esta conduta na investigação dos nossos casos, com exceçāo dos pacientes com trombose venosa central ou com história de trombose venosa de repetição ou ainda com história familiar de trombose, que foram pesquisados para estas deficiências antes de serem classificados como indeterminados $\mathrm{e}$ em raras ocasiōes antes mesmo de realizar angiografia cerebral. Os resultados obtidos na nossa pequena amostra de infartos indeterminados, no mínimo chamam a atenção para o diagnóstico destas deficiências e apontam para necessidade da pesquisa sistemática neste subgrupo específico de pacientes.

Quanto à proporçāo de infartos cerebrais em adultos jovens, secundários a anormalidades hematológicas, diversos autores relataram resultados significativamente diferentes. Bogousslavsky \& Pierre $^{7}$ em sua série de 202 pacientes com menos de 45 anos nem chegaram a destacar as alterações hematológicas como grupo isolado, mas em contrapartida encontraram mais de $20 \%$ de dissecçōes arteriais. Hart \& $\operatorname{Kanter}^{13}$ propuseram que essa proporçāo seria superior a $4 \%$ entre os jovens, enquanto entre os idosos ocorreria em aproximadamente $1 \%$. Adams et al. ${ }^{2}$ relataram $15 \%$ de causas hematológicas em sua série de 144 pacientes. Martinez et al. ${ }^{20}$ relataram 10 (17\%) casos de deficiência de inibidores de coagulação em 60 pacientes testados. Já Barinagarrementeria et al. ${ }^{4}$ descreveram 25\% de estados pró-trombóticos por deficiência de anticoagulantes naturais, de um total de 36 pacientes com menos de 40 anos e IC "idiopático". Enfatizamos que nossa amostragem não nos permite tirar conclusões no que se refere à magnitude desta participação, mas de qualquer modo nos parece precipitado o último relato de $25 \%$ de estados pró-trombóticos como etiologia de IC em pacientes jovens em apenas 36 pacientes testados.

Recentemente tem-se estudado o comportamento destes fatores na fase aguda do infarto. $O$ objetivo destes estudos seria o de determinar sua utilidade como fator prognóstico. Níveis baixos de proteína $C^{3.10}$ indicariam infarto extenso com consumo elevado de fatores fibrinolíticos. Significariam, portanto, mau prognóstico. $O$ papel da proteína $S$ nesta situação é mais complexo e ainda permanece 
indefinido. Mayer et al. ${ }^{22}$,em publicação recente a respeito do tema, reportaram que a deficiência adquirida de proteína $\mathbf{S}$ em pacientes com infarto agudo não constitui fator de mau prognóstico.

Quanto ao tratamento dos pacientes com estas deficiências, existem relatos sugerindo que os anticoagulantes orais (cumarínicos) são eficazes na prevenção de eventos trombóticos recorrentes ${ }^{11}$. Entretanto, o número limitado de pacientes com estes diagnósticos não permitiu até o momento uma conclusão segura pois seria necessário seguimento prolongado de grande número de casos tratados e de grupo controle sem medicação.

Concluindo, nossos resultados sugerem que a dosagem de anticoagulantes naturais nos casos de infartos cerebrais indeterminados deve ser realizada em hospitais de referência. $O$ diagnóstico de estados pró-trombóticos certamente possibilitará uma redução na proporção de casos sem esclarecimento etiológico e significará possibilidade de tratamento especffico nos casos confirmados de deficiência destes fatores. Esta pesquisa deve ser enfatizada nos casos de trombose venosa de repetiçāo, de história familiar de trombose e de múltiplos ICs sem causa aparente após "screening" inicial. Nossos dados até o momento nāo apontam para uma incidência espetacular como relatado por Barinagarrementeria et al.4, mas mostram uma proporção não-negligenciável deste grupo de desordens entre os pacientes jovens com IC no HCRP.

\section{REFERÊNCIAS}

1. Adams HP Jr., Bendixen BH, Kappelle L, Biller J, Love BB, Gordon DL, Marsh EE III and the TOAST Investigators. Classification of subtype of acute ischemic stroke: definitions for use in a multicenter clinical trial. Stroke 1993;24:35-41.

2. Adams HP Jr., Butler MJ, Biller J, Toffol GJ. Nonhemorrhagic cerebral infarction in young adults. Arch Neurol 1986;43:793-796.

3. Anzola GP, Magoni M, Ascari E, Maffi V. Early prognostic factors in ischemic stroke: the role of protein C and protein S. Stroke $1993 ; 24: 1496-1500$.

4. Barinagarrementeria F, Cantú-Brito C, de la Peña A, Izaguirre R. Prothrombotic states in young people with idiopatic stroke. Stroke 1994;25:287-290.

5. Barinagarrementeria F, Cantú-Brito C, lzaguirre R, de la Peña. Progressive intracranial occlusive disease associated with deficiency of protein S. Stroke 1993;24:1752-1756.

6. Bevan H, Sharma K, Bradley W. Stroke in young adults. Stroke 1990;21:382-386.

7. Bogousslavsky J, Pierre P. Ischemic stroke in patients under age 45. Neurol Clin 1992;10:113-124.

8. Chancellor AM, Glasgow GL, Ockelford PA, Johns A, Smith J. Etiology, prognosis, and hemostatic function after cerebral infarction in young adults. Stroke 1989;20:477-482.

9. Cros D, Comp P, Beltran G, Gum G. Superior sagittal sinus thrombosis in a patient with protein S deficiency. Stroke 1990;21:633-636.

10. - D'Angelo A, Landi G, D'Angelo SV, Orazio EN, Boccardi E, Candelise L, Mannucci PM. Protein C in acute stroke. Stroke 1988;18:579-583.

11. Engesser L, Broekmans AW, Briët E, Brommer EJP, Bertina RM. Hereditary protein S deficiency: clinical manifestations. Ann Intern Med 1987;106;677-682.

12. Green D, Otoya J, Oriba H, Rovner R. Protein S deficiency in middle-aged women with stroke. Neurology 1992;42:1029-1033.

13. Hart RG, Kanter MC. Hematologic disorders and ischemic stroke. Stroke 1990;21:1111-1121.

14. Hart RG, Miller VT. Cerebral infarction in young adults: a pratical approach. Stroke 1983;14:110-114.

15. High KA. Antithrombin III, protein C, and protein S: naturally occurring anticoagulant proteins. Arch Pathol Lab Med 1988;112:28-36.

16. Kazui S, Kuriyama Y, Sakata T, Hiroki M, Miyashita K, Sawada T. Accelerated brain infarction in hypertension complicated by hereditary heterozygous protein C deficiency. Stroke 1993;24:2097-2103.

17. Kilpatrick TJ, Matkovic Z, Davis SM, McGrath CM, Dauer RJ. Hematologic abnormalities occur in both cortical and lacunar infarction. Stroke 1993;24:1945-1950.

18. Kohler J, Kasper J, Witt I, Reutern G-M. Ischemic stroke due to protein C deficiency. Stroke 1990;21:1077-1080.

19. Lagosky W, Witten CM. A case of cerebral infarction in association with free protein $S$ deficiency and oral contraceptive use. Arch Phys Med Rehabil 1993;74:98-100.

20. Martinez HR, Rangel-Guerra RA, Marfil LJ. Ischemic stroke due to deficiency of coagulation inhibitors: report of 10 young adults. Stroke 1993;24:19-25.

21. Matsushita K, Kuriyama Y, Sawada T, Uchida K. Cerebral infaction associated with protein C deficiency. Stroke 1992;23:108-111.

22. Mayer SA, Sacco RL, Hurlet-Jensen A, Shi T, Mohr JP. Free protein S deficiency in acute ischemic stroke. Stroke 1993:24:224-227.

23. Sacco RL, Owen J, Mohr JP, Tatemichi TK, Grossman BA. Free protein S deficiency: a possible association with cerebrovaseular occlusion. Stroke 1989;20:1657-1661.

24. Wintzen AR, Brockmans AW, Bertina RM, Briët E, Briët PE, Zecha A, Vielvoye GJ, Bots GThAM, Cerebral haemorthagic infarction in young patients with hereditary protein $C$ deficiency: evidence for "spontaneous" cerebral venous thrombosis, $B r$ Med J 1985;290:350-352. 